9 Graduate School of Natural Science \& Technology, Kanazawa University, Kakuma, Kanazawa \section{and Radish Growth (Raphanus sativus L.) \\ Effect of Biodegradable Chelating Ligand on Iron Bioavailability}

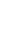

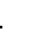

(1)

\author{
H. Hasegawa*; M. Azizur Rahman; K. Saitoh; T. Maki; K. Ueda
}

6

(1)

8

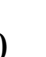

(1)

1

2

3

4

\section{*Corresponding author}

E-mail: hhiroshi@t.kanazawa-u.ac.jp

Tel/Fax: 81-76-234-4792 


\section{Abstract:}

26 The effect of chelating ligands on iron uptake and growth of radish (Raphanus sativus L.) was

27 investigated. The ethylenediaminetetraacetic acid (EDTA) increased ${ }^{55} \mathrm{Fe}$ uptake in roots of

28 radish though its subsequent translocation from roots to shoots and leaves did not increased.

29 About $70 \%-80 \%$ of the total ${ }^{55} \mathrm{Fe}$ was distributed in the roots while about 5\%-15\% and $11 \%-17 \%$

30 were in shoots and leaves, respectively. The EDTA increases iron uptake into the roots of radish,

31 but not in the above ground parts of the plant. The growth of radish (Raphanus sativus L.)

32 decreased drastically in alkaline condition $(\mathrm{pH}>9)$, even though the concentration of iron was

33 sufficient in the growth medium. The growth of radish was enhanced successfully by the

34 addition of hydroxyiminodisuccinic acid (HIDS) and EDTA. This might be because HIDS and

35 EDTA solubilize iron from its precipitation with hydroxides at higher $\mathrm{pH}$, and increase iron

36 bioavailability. The influence of EDTA and HIDS on radish growth was comparable. Increase of

37 radish growth by ethylenediaminedisuccinic acid (EDDS) and methylglicinediacetic acid

38 (MGDA) was less than those by EDTA and HIDS. Considering the reproducibility of the radish

39 growth (biomass production) at $\mathrm{pH}$ 10, HIDS is supposed to be more effective compared to

40 EDTA.

Keywords: Iron (Fe), Chelating ligands, Radish (Raphanus sativus L.), HIDS, Bioavailability. 


\section{Introduction:}

Iron is an essential micronutrient for plants, which plays important roles in respiration,

52 photosynthesis, and many other cellular functions such as DNA synthesis, nitrogen fixation, and

53 hormone production (Vert et al. 2002). Although abundant in nature, iron often is unavailable to

54 plants, especially at neutral or alkaline $\mathrm{pH}$, because it forms insoluble ferric hydroxide

55 complexes in the presence of oxygen (Cohen et al. 1998; Guerinot and Yi 1994). The

56 precipitation of iron hydroxide is also known as iron plaque. Iron plaque formation in the

57 rhizosphere, however, may results iron deficiency to the plants. Plants use two distinct strategies

58 to assimilate iron from the environment. Grasses release low molecular weight and high affinity

59 Fe(III)-chelate compounds called phytosiderophores, which solubilize ferric iron in the

60 rhizosphere and are recognized for uptake by specific membrane transporters (Bienfait 1988;

61 Chaney 1987; Romheld and Marschner 1986). Iron uptake in dicots and nongrass monocots is

62 mediated by a plasma membrane-bound ferric reductase that transfers electrons from

63 intracellular NADH (Buckhout et al. 1989) to $\mathrm{Fe}(\mathrm{III})$-chelates in the rhizosphere (Chaney,

64 Brown, and Tiffin 1972). The ferrous ions $\left(\mathrm{Fe}^{2+}\right)$ released from the chelates by this process are

65 subsequently transported into the cytoplasm via a separate transport protein (Kochian 1991; Fox 66 et al. 1996).

67

In iron deficient condition, dicots and nongrass monocots stimulate a number of

69 processes to enhance iron accumulation from the soil. Root-mediated acidification of rhizosphere

70 by iron deficient plants to enhance solubilization of $\mathrm{Fe}^{3+}$ from iron hydroxides is an interesting

71 strategy (Chaney, Brown, and Tiffin 1972; Bienfait et al. 1983). In nature, rhizospheric microbes

72 have been reported to exude siderophores to the root-plaque interface. These siderophores

73 solubilize ferric iron in the rhizosphere and are recognized for uptake by specific membrane 
74 receptors and render its phytoavailibility (Bienfait 1988; Chaney 1987; Romheld and Marschner 75 1986).

Research on the interaction of plants with chelating ligands started in the 1950s with a

78 view to alleviating deficiencies in the essential nutrients $\mathrm{Fe}, \mathrm{Mn}, \mathrm{Cu}$, and $\mathrm{Zn}$ (Wenger, Tandy, 79 and Nowack 2005). EDTA has become very popular to achieve this purpose but has the

80 disadvantage that it is quite persistent in the environment due to its low biodegradability. EDTA

81 also impairs plant growth severely, even at very low concentrations. Therefore, biodegradable

82 chelating ligands could be the best alternatives to EDTA for the increase of iron availability to

83 plants. The biodegradable chelating ligands would solubilize precipitated iron in the rhizosphere

84 without any harmful environmental effects. In this study, we investigated the effects of

85 biodegradable chelating ligands on growth of radish (Raphanus sativus L.), and iron uptake by

86 the plant at different $\mathrm{pH}$. Our research approach was to increase iron phytoavailibility using

87 biodegradable chelating ligands, when iron becomes unavailable because of its precipitation with 88 hydroxides.

\section{Materials and Methods:}

\section{$91 \quad$ 2.1. Experimental setup}

Before use in the experiment, seeds of radish were stored in refrigerator at $4^{\circ} \mathrm{C}$. They

93 were sterilized with $0.25 \% \mathrm{NaClO}$ and $25 \mu \mathrm{M}$ Tween20 solution for two minutes, and rinsed

94 with $5 \mathrm{ml}$ of deionized water using an E-pure system (Barnstead) for five times. The standard

95 Murashige and Skoog (MS) growth medium was modified using 0 and $10 \mu \mathrm{M} \mathrm{FeCl} \cdot 6 \mathrm{H}_{2} \mathrm{O}$ for

96 Fe-deficient and -sufficient condition, respectively (Table 1). $10 \mathrm{mM}$ chelating ligand were used

97 in the MS medium before the cultivation of radish. Seeds were grown on $4 \mathrm{ml}$ of modified MS

98 medium in a 14-ml sterilized polystyrene tube. After screening from light for 3 days, the plants 
99 were grown in a growth chamber, where the condition was set as 14:10 h light/dark schedule,

$100180 \mu \mathrm{M}$ photon $\mathrm{m}^{-2} \mathrm{~s}^{-1}$ light intensity from cool white fluorescent lights and $20{ }^{\circ} \mathrm{C}$ temperatures.

101 The experiments were run for 2-3 weeks. For the measurement of dry-weight, plant samples

102 were dried at $90{ }^{\circ} \mathrm{C}$ until they reached a constant weight.

103

104

\subsection{Extraction of extracellular fractions of iron and chemical analysis}

105 Extra and intracellular fractions of iron in radish were determined by radiochemical 106 measurements of ${ }^{55} \mathrm{Fe}$. For intracellular iron, samples were successively rinsed with $5 \mathrm{ml}$ of 107 deionized water, $5 \mathrm{ml}$ of $0.047 \mathrm{M}$ Ti(III)-citrate-EDTA solution and again with $5 \mathrm{ml}$ of deionized 108 water. For total iron (corresponding to intra and extracellular iron), other samples were rinsed 109 with $5 \mathrm{ml}$ of EPW. Both of the samples, in which ${ }^{55}$ Fe retained as a tracer, were directly added 110 to $5 \mathrm{ml}$ of liquid scintillation solutions [3.0 g of 2-(4-tert-butylphenyl)-5-(4-biphenylyl)-1,3,4111 oxadiazole / $500 \mathrm{ml}$ toluene] in $20 \mathrm{ml}$ vials. Radiochemical activity of ${ }^{55} \mathrm{Fe}$ was measured using 112 the tritium mode of the liquid scintillation counter (LSC-6101, Aloka, Japan). The concentration 113 of $\mathrm{Fe}(\mathrm{III})$ was calculated from $\mathrm{Fe}(\mathrm{III}) /{ }^{55} \mathrm{Fe}(\mathrm{III})$ ratio in sample solutions.

\section{$115 \quad$ 2.3. Chemicals}

116 Stock solution of $\mathrm{Fe}(\mathrm{III})$ was prepared by dissolving $\mathrm{FeCl}_{3} \cdot 6 \mathrm{H}_{2} \mathrm{O}$ (Nacalai Tesque, 117 Kyoto) in 1M HCl (TAMAPURE-AA-100, Tama Chemicals, Tokyo) and was standardized by 118 using inductively coupled plasma atomic emission spectrometry (Optima 3300XL, Perkin-Elmer, 119 USA). Stock solution of ${ }^{55} \mathrm{Fe}(\mathrm{III})$ was prepared by dissolving ${ }^{55} \mathrm{FeCl}_{3}$ (PerkinElmer Life \& 120 Analytical Sciences, specific activity; >111 GBq/g, 37MBq) in 1M HCl (TAMAPURE-AA121 100). They were diluted to the desired concentration ratios of Fe $/{ }^{55} \mathrm{Fe}$. Stock solutions of EDTA, 122 HIDS, IDS, MGDA and EDDS were prepared by dissolving ethylenediamine-N,N,N',N'123 tetraacetic acid (Dojindo Molecular Technologies, Japan), tetrasodium 3-hydroxy-2,2’- 
124 iminodisuccinate (Nippon Syokubai, Japan), tetrasodium iminodisuccinate (Bayer), 125 methylglycine-N,N-diacetic acid (BASF) and ethylenediamine-N, N'-disuccinic acid (Chelest) in $126 \quad 0.1 \mathrm{M}$ sodium hydroxide, respectively. Other reagents were of analytical grade or better. All 127 solutions were prepared with deionized water.

\section{Results and Discussions}

\section{1. ${ }^{55} \mathrm{Fe}$ uptake in tissues of radish influenced by EDTA}

${ }^{55} \mathrm{Fe}$ uptake in roots of radish seedling was increased by EDTA though its translocation

132 from roots to shoots and leaves was not increased (Fig. 1). About 68\%, 15\% and 17\% of the total 133 iron was accumulated in roots, stems and leaves of radish, respectively, when EDTA was not 134 added to the growth medium. With the addition of EDTA to the growth medium, the amounts 135 changed to $84 \%, 5 \%$ and $11 \%$ in roots, stems and leaves, respectively. It is important that iron 136 uptake in roots increased by 22\% with the addition of EDTA in the culture medium though iron 137 translocation from roots to stems and leaves decreased by $66 \%$ and $33 \%$, respectively after the 138 addition of EDTA to the growth medium. The results elucidate that chelating ligands increase 139 iron uptake into plant's roots, but iron translocation from roots to above ground parts of plants 140 might not be affected by its concentrations in roots. Plants translocate iron from roots to aerial 141 parts according to their needs.

144 due to photosynthesis in leaves of green plants. Green plants translocate most of the iron to the

145 leaves to perform photosynthesis, in which many metabolic processes are activated by iron (Briat 146 et al. 1995; Hendry and Rocklebank 1985; Kampfenkel, Van Montagu, and Inze 1995; Prescott 147 and John 1996; Somers and Shive 1942), and iron itself is a prosthetic group of many enzymes 148 (Janneke and Stéphane 2005; Knaff 2004). Iron is an essential micronutrient for plants, which 
149 plays important roles in respiration, photosynthesis, and many other cellular functions such as

150 DNA synthesis, nitrogen fixation, and hormone production (Vert et al. 2002).

151

\subsection{Radish growth affected by Fe at different $\mathrm{pH}$}

Radish (Raphanus sativus L.) was grown with and without Fe(III) at different pH ranged

154 between 7 and 10. Biomass productions of radish were almost constant in the $\mathrm{pH}$ range of 7-9 in

155 the nutrient medium. However, biomass production of the plant was about 62-73\% higher in 156 solutions with $10 \mu \mathrm{M}$ iron than those without iron (Fig. 2). At pH 10, radish growth decreased

157 drastically. The dry biomass of the plant was $14.04 \pm 7.92 \mathrm{mg}$ and $12.52 \pm 5.50 \mathrm{mg}$ in nutrient

158 solution with iron and without iron, respectively. The result implies that the influence of iron on

159 plant growth is directly related to the $\mathrm{pH}$ of the growth medium.

Iron plays important roles in photosynthesis in plants (Vert et al. 2002). Although iron is

162 sufficient in growth medium, its availability is mostly dependent on $\mathrm{pH}$. In alkaline $\mathrm{pH}$ condition

163 iron forms insoluble ferric hydroxide complexes in the presence of oxygen (Cohen et al. 1998).

164 Iron deficiency results chlorosis in green leaves, which retards plant growth, and leads to the 165 reduction of crop yields (Guerinot and Yi 1994). The results of the present study also showed 166 that radish growth decreased drastically at higher $\mathrm{pH}$, which might be the consequence of iron 167 chlorosis.

\section{3.3. Influence of chelating ligands and $\mathrm{pH}$ on radish growth}

The influence of chelating ligands and $\mathrm{pH}$ of the growth medium on biomass production

171 of radish was studied. Results show that biomass production decreased drastically at $\mathrm{pH} 10$, 172 when chelating ligands were not applied (Fig. 3). This was due to the drastic reduction of iron 173 availability to the plant because of insoluble ferric hydroxide formation. The depletion in 
174 biomass production was enhanced up to $29 \%$ and $31 \%$ by the addition of HIDS and EDTA in the

175 growth medium, respectively. However, EDDS was ineffective in the increase of biomass 176 production of the plant (Fig. 3). The result suggests that the efficiency of HIDS in the increase of

177 iron phytoavailibility at higher $\mathrm{pH}$ is comparable with that of EDTA. Thus, HIDS, a 178 biodegradable chelating ligand, would be alternative to environmentally persistent and non179 biodegradable EDTA.

Biomass production of radish was about $10-31 \%$ worse compared to the control

182 treatments (without chelating ligands) even after the addition of chelating ligands in the growth 183 medium (Fig. 3). The highest depletion (52\%) in biomass was observed in EDDS treated radish 184 at $\mathrm{pH}$ 9. It can be concluded from the results that chelating ligands are effective in the increase of 185 plant growth at higher $\mathrm{pH}(>10)$. The use of chelating ligands at lower $\mathrm{pH}(<9)$ would produce 186 negative results, as observed in the present study.

Radish was also grown at pH 10, with and without chelating ligands and iron (Fig. 4).

189 Results show that plant biomass was lowest $(13.00 \pm 5.50 \mathrm{mg})$, when both iron and ligand were 190 not applied to the medium. With the addition of $10 \mu \mathrm{M}$ of Fe(III), biomass of EDDS and MGDA

191 treated radish did not differ from the control treatment (without chelating ligand). The plant 192 biomass production was increased by 17\%, 29\%, and 31\% with the addition of IDS, HIDS, and 193 EDTA, respectively (Fig. 4). Considering the reproducibility with the smaller standard deviation, 194 HIDS appears to be better chelating ligand for the increase of plant growth.

\subsection{Effect of chelating ligands on height and fresh biomass production of radish}

Radish (Raphanus sativus L.) was grown in alkaline growth medium (pH 10) containing 
199

200

201

202

203

204

205

206

207

208

209

210

211 (Janneke and Stéphane 2005; Knaff 2004). the increase of iron uptake by chelating ligands.

precipitated, and iron phytoavailibility decreased significantly. In the present study, it was observed that chelating ligands increased iron uptake into radish plant, which results in the increase of the plant growth (biomass production) (Fig. 4). It was also observed that some chelating ligands increased plant height compared to the control one (Fig. 5). It might be due to

Plant height is an important parameter of growth. Auxin and gibberellin are mainly responsible for the cell elongation leading to the increase of plant height (Rayle and Cleland 1992; Yang, Davies, and Reid 1996). Although information about the direct role of iron in the plant cell elongation is limited, iron might play important role in plant elongation as it is involved in many metabolic processes of plant (Hendry and Rocklebank 1985; Kampfenkel, Van Montagu, and Inze 1995; Vert et al. 2002), and as it is a prosthetic group of many enzymes

\section{Conclusion:}

The use of chelating ligands, especially EDTA, has been widely applied from long time

215 for the increase of iron phytoavailibility. EDTA used for this purpose for long time. Recently, 216 leaching of metals due to the huge application of EDTA in the crop fields, and the non217 biodegradability of EDTA raise the question whether this chelating ligand would be used any 218 more or not. Therefore, ascertain of an effective substitute of EDTA with biodegradable 219 characteristics comes in the focus of scientific community in this field. The present study was 220 initiated keeping this point in mind. This article describes the preliminary findings of the study. 221 From our study, we propose HIDS as the best alternative to EDTA for the increase of iron 222 phytoavailibility at alkaline $\mathrm{pH}$. More investigation is needed to establish this proposal. 
224

225

226

227

228

229

230

231

232

233

234

235

236

237

238

239

240

241

242

243

244

245

246

\section{Acknowledgements:}

This research was supported partly by Grants-in-Aid for Scientific Research (18510071) from the Japan Society for the Promotion of Science (JSPS).

\section{References}

Bienfait, H. F. 1988. Mechanisms in Fe-efficiency reactions of higher plants. Journal of Plant Nutrition 11:605-629.

Bienfait, H. F., R. J. Bino, A. M. Bliek, J. F. Duivenvoorden, and J. M. Fontaine. 1983. Characterization of ferric reducing activity in roots of Fe-deficient Phaseolus vulgaris. Physiologia Plantarum 59 (2):196-202.

Briat, J. F., I. Fobis-Loisy, N. Grignon, S. Lobreaux, N. Pascal, G. Savino, S. Thoiron, N. von Wiren, and O. Van Wuytswinkel. 1995. Cellular and molecular aspects of iron metabolism in plants. Biology of the Cell 84:69-81.

Buckhout, Thomas J., Paul F. Bell, Douglas G. Luster, and Rufus L. Chaney. 1989. Iron-Stress Induced Redox Activity in Tomato (Lycopersicum esculentum Mill.) Is Localized on the Plasma Membrane. Plant Physiology 90 (1):151-156.

Chaney, R. L. 1987. Complexity of iron nutrition: Lessons for plan-soil interaction research. Journal of Plant Nutrition 10:963-994.

Chaney, Rufus L., John C. Brown, and Lee O. Tiffin. 1972. Obligatory Reduction of Ferric Chelates in Iron Uptake by Soybeans. Plant Physiology 50 (2):208-213.

Cohen, Clara K., Tama C. Fox, David F. Garvin, and Leon V. Kochian. 1998. The Role of IronDeficiency Stress Responses in Stimulating Heavy-Metal Transport in Plants. Plant Physiology 116 (3):1063-1072. 
247 Fox, T. C., J. E. Shaff, M. A. Grusak, W. A. Norvell, Y. Chen, R. L. Chaney, and L. V. Kochian. 1996. Direct Measurement of 59Fe-Labeled Fe2+ Influx in Roots of Pea Using a Chelator Buffer System to Control Free Fe2+ in Solution. Plant Physiology 111 (1):93-100.

Guerinot, M. L., and Y. Yi. 1994. Iron: Nutritious, Noxious, and Not Readily Available. Plant Physiology 104 (3):815-820.

Hendry, G. A. F. , and K. J. B. Rocklebank. 1985. Iron-Induced Oxygen Radical Metabolism in Waterlogged Plants. New Phytologist 101 (1):199-206.

Janneke, B., and L. Stéphane. 2005. Biogenesis of iron-sulfur proteins in plants. Trends in Plant Science 10 (7):324-331.

Kampfenkel, K., M. Van Montagu, and D. Inze. 1995. Effects of Iron Excess on Nicotiana plumbaginifolia Plants (Implications to Oxidative Stress). Plant Physiology 107 (3):725735.

Knaff, D. B. 2004. Ferredoxin and ferredoxin-dependent enzymes. Netherlands: Springer

Kochian, L. V. 1991. Mechanisms of micronutrient uptake and translocation in plants. Madison, WI: Soil Science Society of America.

Prescott, Andy G., and Philip John. 1996. DIOXYGENASES: Molecular Structure and Role in Plant Metabolism. Annual Review of Plant Physiology and Plant Molecular Biology 47 (1):245.

Romheld, Volker, and Horst Marschner. 1986. Evidence for a Specific Uptake System for Iron alive and well. Plant Physiology 99 (4):1271-1274. Phytosiderophores in Roots of Grasses. Plant Physiology 80 (1):175-180. Physiology 17 (4):582-602. 
271 Vert, Gregory, Natasha Grotz, Fabienne Dedaldechamp, Frederic Gaymard, Mary Lou Guerinot, 272 Jean-Francois Briat, and Catherine Curie. 2002. IRT1, an Arabidopsis Transporter 273 Essential for Iron Uptake from the Soil and for Plant Growth. Plant Cell 14 (6):12232741233.

275 Wenger, K., S. Tandy, and B. Nowack. 2005. Effects of chelating agents on trace metal 276 speciation and bioavailability. Vol. 910. Washington, DC.: American Chemical Society.

277 Yang, T., P. J. Davies, and J. B. Reid. 1996. Genetic Dissection of the Relative Roles of Auxin 278 and Gibberellin in the Regulation of Stem Elongation in Intact Light-Grown Peas. Plant Physiology 110 (3):1029-1034.

280

281

282

283

284

285

286

287

288

289

290

291

292

293

294

295 
296 Table 1: Composition of modified Murashige and Skoog (MS) medium used for radish 297 (Raphanus sativus L.) growth.

298

\begin{tabular}{|c|c|}
\hline Compounds & $\left(\mathrm{mg} \mathrm{l}^{-1}\right)$ \\
\hline $\mathrm{NH}_{4} \mathrm{NO}_{3}$ & 1650 \\
\hline $\mathrm{KNO}_{3}$ & 1900 \\
\hline $\mathrm{CaCl}_{2} \cdot 2 \mathrm{H}_{2} \mathrm{O}$ & 440 \\
\hline $\mathrm{MgSO}_{4} \cdot 7 \mathrm{H}_{2} \mathrm{O}$ & 370 \\
\hline $\mathrm{KH}_{2} \mathrm{SO}_{4}$ & 170 \\
\hline $\mathrm{H}_{3} \mathrm{BO}_{3}$ & 6.2 \\
\hline $\mathrm{MnSO}_{4} \cdot 4 \mathrm{H}_{2} \mathrm{O}$ & 22.3 \\
\hline $\mathrm{ZnSO}_{4} \cdot 7 \mathrm{H}_{2} \mathrm{O}$ & 8.6 \\
\hline KI & 0.83 \\
\hline $\mathrm{Na}_{2} \mathrm{MoO}_{4} \cdot 2 \mathrm{H}_{2} \mathrm{O}$ & 0.25 \\
\hline $\mathrm{CuSO}_{4} \cdot 5 \mathrm{H}_{2} \mathrm{O}$ & 0.025 \\
\hline $\mathrm{CoCl}_{2} \cdot 6 \mathrm{H}_{2} \mathrm{O}$ & 0.025 \\
\hline Thiamine hydrochloride & 15 \\
\hline Nicotinic acid & 25 \\
\hline Pyridoxine hydrochloride & 0.25 \\
\hline Sucrose & 30000 \\
\hline Agar & 18000 \\
\hline
\end{tabular}




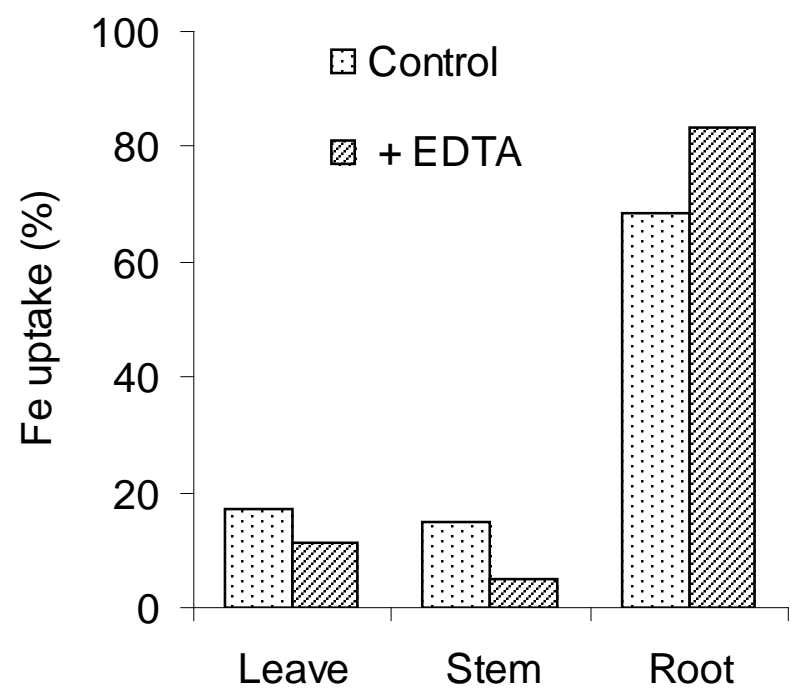

302

303 Fig.1: Effect of EDTA on iron $\left({ }^{55} \mathrm{Fe}\right)$ uptake in different parts of radish (Raphanus sativus L.).

304

305

306

307

308

309

310

311

312

313

314

315

316

317

318 


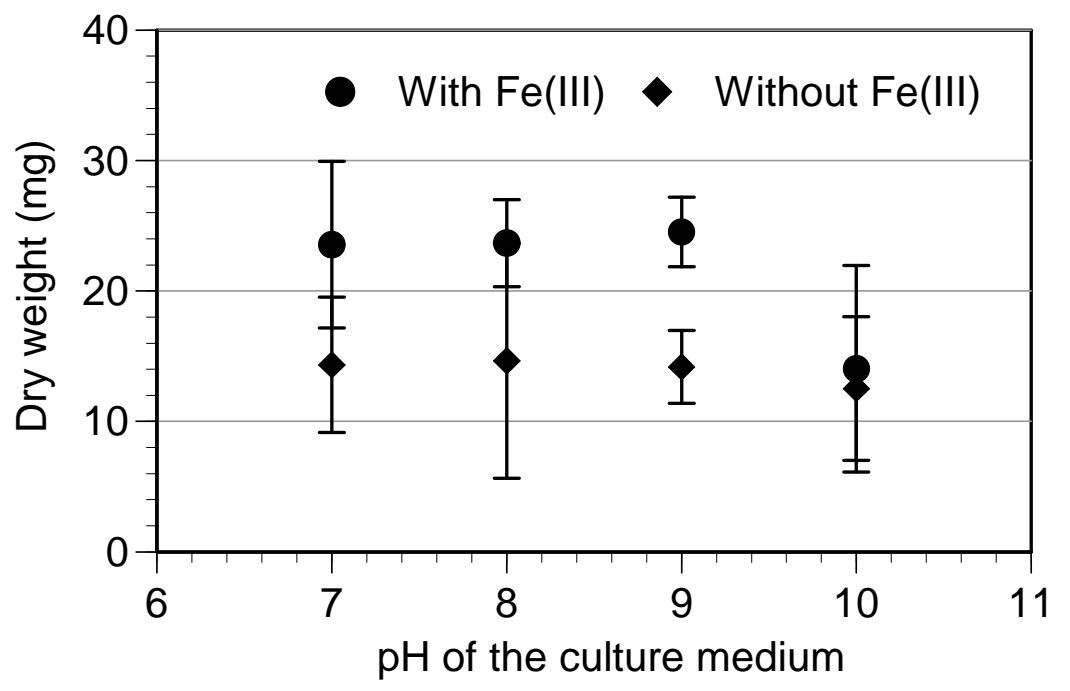

320

321 Fig. 2: Growth of radish (Raphanus sativus L.) affected by iron at different $\mathrm{pH}$.

322

323

324

325

326

327

328

329

330

331

332

333

334

335

336 

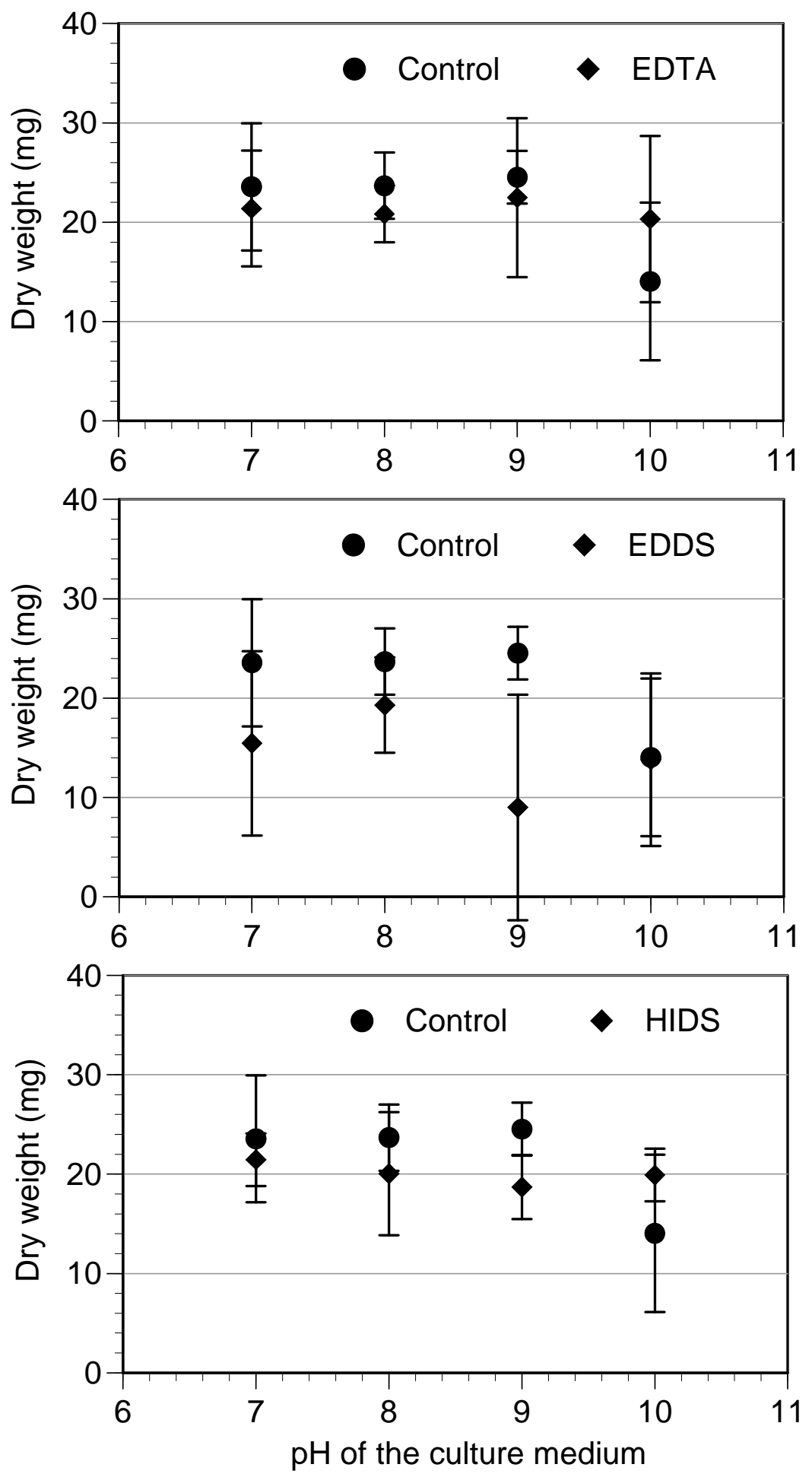

339 Fig. 3: Effect of chelating ligands on radish (Raphanus sativus L.) growth. Concentrations of 340 chelating ligands (EDTA, EDDS, and HIDS) and Fe(III) in growth medium were $10 \mathrm{mM}$ and 10 $341 \mu \mathrm{M}$, respectively. 


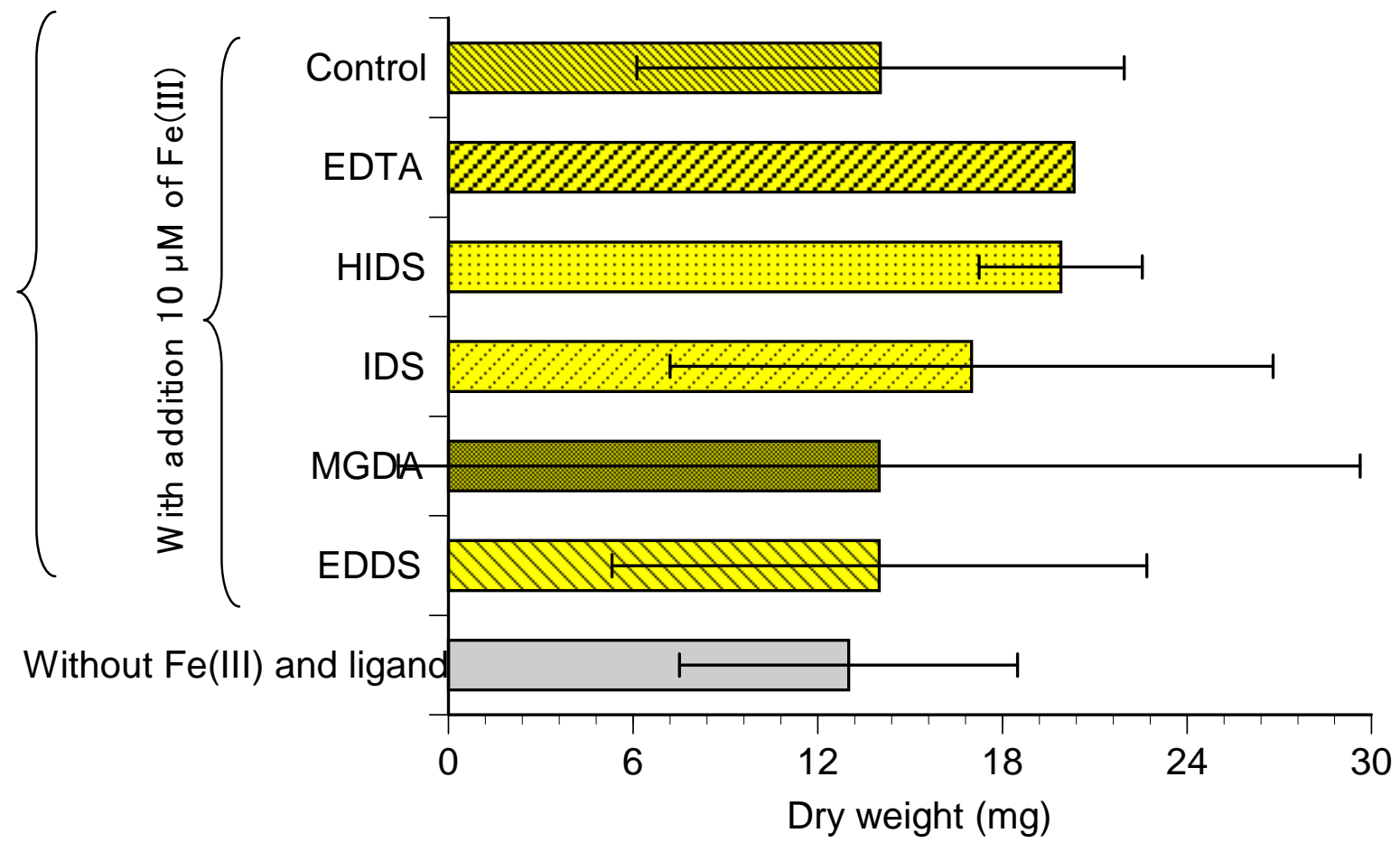

344 Fig. 4: Effects of chelating ligands and Fe(III) on growth of radish (Raphanus sativus L.) in 345 alkaline condition ( $\mathrm{pH} 10)$.

346 


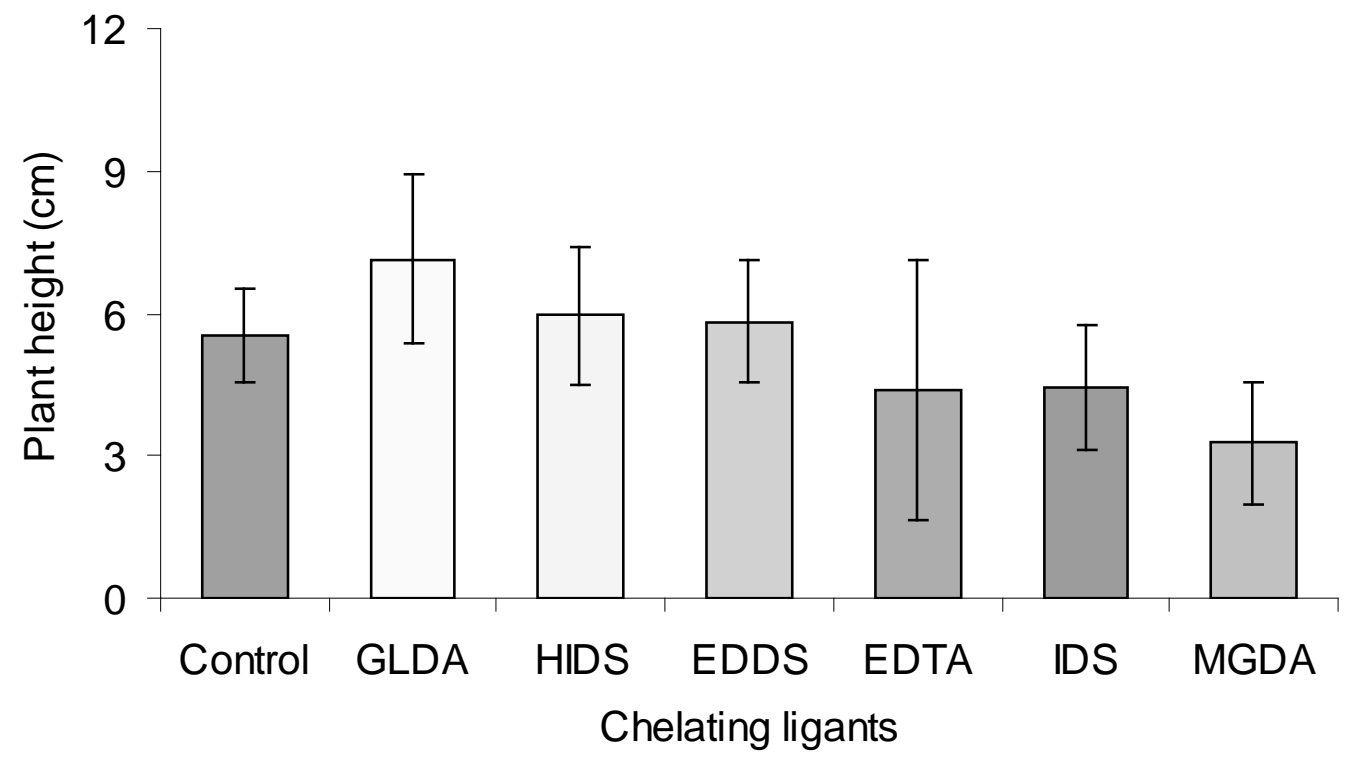

359 Fig. 5: Effect of chelating ligands on height of radish (Raphanus sativus L.) in alkaline condition

360 ( $\mathrm{pH}$ 10). Concentrations of chelating ligands and Fe(III) in growth medium were $10 \mathrm{mM}$ and 10 $361 \mu \mathrm{M}$, respectively. 